\title{
Gestión estatal del hábitat y segregación residencial. Incertidumbre, participación y reclamo en un conflicto habitacional
}

Soledad Balerdi

Doctora en Ciencias Sociales por la Universidad Nacional de La Plata y la Universidad de Amberes (Bélgica). Becaria posdoctoral de CONICET y docente de la Facultad de Humanidades y Ciencias de la Educación de la Universidad Nacional de La Plata. Instituto de Investigación en Humanidades y Ciencias Sociales (FaHCE/UNLP-CONICET).

soledadbalerdi@gmail.com

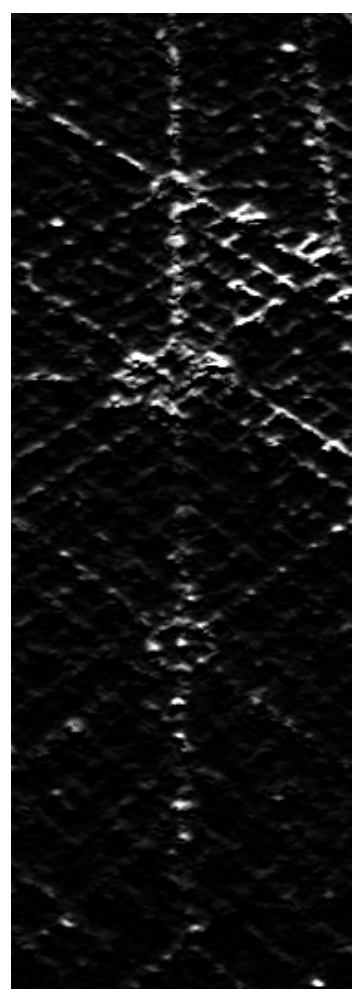

http://dx.doi.org/10.30972/crn.30304925 


\section{Gestión estatal del hábitat y segregación residencial. Incertidumbre, participación y reclamo en un conflicto habitacional}

\section{Resumen}

Este artículo reflexiona sobre la intervención del Estado en la producción del espacio urbano a través de políticas habitacionales orientadas a garantizar el acceso a la tierra y a la vivienda por parte de los sectores populares. En concreto, analiza los efectos de esta intervención en relación con la segregación residencial de estas poblaciones, así como con las posibilidades que habilita para el establecimiento de demandas populares en torno al hábitat. Para ello, a partir de un trabajo etnográfico, se enfoca en el análisis de un conflicto por relocalizaciones en un barrio popular de la ciudad de La Plata.

\section{Palabras clave}

Estado; políticas habitacionales; relocalización; demanda.

\section{State management of habitat and residential segregation. Uncertainty, participation and claim in a housing conflict}

\begin{abstract}
This article reflects on the intervention of the State in the production of urban space through housing policies aimed at guaranteeing access of popular sectors to land and housing. Specifically, it analyzes the effects of this intervention in relation to the residential segregation of these populations, as well as the possibilities that it enables for the establishment of popular demands on habitat. With this aim, based on an ethnographic work, the article focuses on the analysis of a conflict over relocations in a popular neighborhood of the city of La Plata.
\end{abstract}

\section{Keywords}

State; housing policies; relocation; demands.

\section{Gestão estadual do habitat e segregação residencial. Incerteza, participação e reclamação em um conflito habitacional}

\section{Resumo}

Este artigo reflete sobre a intervenção do Estado na produção do espaço urbano por meio de políticas habitacionais voltadas para a garantia do acesso à terra e à moradia pelos setores populares. Especificamente, analisa os efeitos dessa intervenção em relação à segregação residencial dessas populações, bem como as possibilidades que ela habilita para o estabelecimento de demandas populares no entorno do habitat. Para isso, a partir de um trabalho etnográfico, centra-se na análise de um conflito de relocação em um bairro popular da cidade de La Plata.

\section{Palavras-chave}

Estado; políticas habitacionais; relocação; demanda. 


\section{El Estado en la producción del espacio urbano. Mejoras y desigualdades persistentes}

Este artículo reflexiona sobre las modalidades de intervención del Estado en materia de producción del espacio urbano, a partir de un conflicto por relocalizaciones que tuvo lugar en un barrio popular de la ciudad de La Plata en los años 2014 y 2015. En función del análisis de este caso, se buscará sostener el argumento de que el Estado intervino activamente en la producción del espacio urbano a través de políticas habitacionales orientadas a garantizar el acceso de los sectores populares al suelo y a la vivienda, pero que esa intervención no estuvo exenta de tensiones, abrió conflictos y tuvo consecuencias ambivalentes para los beneficiarios de dichas políticas, contribuyendo en muchos casos a reforzar la segregación residencial de las poblaciones más vulnerables. En este caso en particular, se buscará mostrar cómo, a través del Ministerio de Infraestructura de la provincia de Buenos Aires, el Estado llevó adelante un plan de relocalización de viviendas en la ciudad de La Plata gestionando y generando incertidumbre, y a la vez habilitando un reclamo por parte de los habitantes.

El contexto en el que se enmarca este artículo está caracterizado por el despliegue de una batería de políticas habitacionales que llevó a cabo el gobierno nacional durante el período kirchnerista (2003-2015), que implicó considerables mejoras en el acceso a la vivienda por parte de los sectores sociales más desfavorecidos, pero que al mismo tiempo convivió con desigualdades estructurales persistentes en materia habitacional que, a pesar de las acciones emprendidas, no lograron ser revertidas.

En efecto, a partir de los años 2003 y 2004 el gobierno de Kirchner impulsó una nueva batería de políticas habitacionales en el marco de una situación de emergencia social tras la crisis de 2001. El Programa Federal de Construcción de Viviendas, el Programa Federal de Mejoramiento de Viviendas Mejor Vivir, así como el Subprograma de Urbanización de Villas y Asentamientos y el de Construcción de Viviendas con Municipios, entre otros (BetTatis, 2009), se inscribirían en una nueva modalidad de intervención "recentralizada" del Estado en los barrios, orientada hacia "la producción de vivienda nueva para los sectores desprotegidos" (FERRAUdi CURTo, 2014, p. 116) y como estrategia de reactivación de la economía, buscando revertir los efectos de la crisis. Contra la orientación focalizada y descentralizada de la política 
habitacional de las décadas precedentes, esta iniciativa federal "reposicionó al Estado como actor clave del sector" (Di VirgiLIo \& RodRíGuez, 2018, p. 183), y se convirtió en una oportunidad inigualable para la intervención pública en la producción del espacio urbano.

No obstante, a pesar de estos esfuerzos, el mercado inmobiliario continuó permeando las condiciones de acceso a la vivienda (Di Virgilio \& Rodríguez, 2018, p. 184), y las empresas constructoras mantuvieron un lugar relevante en la ejecución de estas políticas (BARRETO, 2012). En este escenario, y dada la magnitud del déficit habitacional existente, los logros de la política habitacional desplegada en el período kirchnerista fueron limitados: "en doce años, a pesar de los esfuerzos, se logró atender alrededor de un $27 \%$ del déficit habitacional total estimado" (Di Virgilio \& RodríGuez, 2018, p. 216).

Haciendo un balance de la década 2003-2013, GABRIEL KessLER (2014) sostiene que en el período se advierte el mejoramiento de distintos indicadores de vivienda y hábitat en relación con las décadas precedentes, pero estas mejoras conviven con desigualdades persistentes, dos tendencias que el autor denomina "contrapuestas" para caracterizar a la década kirchnerista. Estas mejoras no lograron revertir "la desigualdad entre provincias y entre la ciudad formal y las áreas urbanas más marginadas” (KEssLER, 2014, p. 173). Para el caso de las villas y asentamientos en particular, el autor sostiene que el período evidencia un aumento de su población, como resultado de diversos procesos vinculados con las dificultades de acceso a la tierra y la vivienda. Entre ellos señala la concentración de oportunidades laborales en los grandes centros urbanos, que conduce a una mayor competencia por el suelo entre sectores sociales y el incremento de la renta urbana producto de la reactivación económica general (KESSLER, 2014).

En el caso del Gran La Plata, Di Croce Garay y Alessio (2018) identifican un incremento en la cantidad de asentamientos informales, no solo de la población de los ya existentes. GonzÁLEz (2014, p. 1256) sostiene que esta paradoja de expansión de las villas y asentamientos en una década de crecimiento económico y disminución de la pobreza puede explicarse por una combinación de factores que tienen que ver con la política liberal en materia de suelo y la hegemonía del mercado inmobiliario en los procesos de urbanización. Pero también con ciertas características del nuevo contexto político que se inicia en 2003 y que marca un cambio importante con las décadas anteriores: la menor tendencia a la represión y el desalojo de tomas; la mejora en las condiciones de ingreso de las familias de los sectores populares, que les permite contar con una disponibilidad mayor de recursos para la autoconstrucción 
(estrategia central de acceso al hábitat por parte de los sectores populares en las ciudades latinoamericanas), sumado finalmente al hecho de que las organizaciones sociales constituidas a fines de los años 90 en torno al eje de la desocupación fueron incorporando a sus reclamos la cuestión de la tierra y la vivienda en los barrios populares.

En este marco, otro elemento central que contribuirá con la persistencia de las desigualdades en un escenario de mayor intervención y mejoras relativas en materia habitacional estará dado por la modalidad de producción de ciudad que adoptarán las políticas habitacionales del período: la construcción de las nuevas viviendas en tierras disponibles y baratas. La segregación residencial estará vinculada íntimamente con la lógica del mercado del suelo (Cravino, 2012; Duhau, 2013), pero también con las políticas habitacionales que tenderán a relegar a los barrios populares erigidos a partir de procesos de relocalización o programas de urbanización a las zonas más desvalorizadas de las ciudades (SEGURA, 2014).

Este artículo se basa en un trabajo etnográfico realizado en un barrio popular de La Plata, el barrio La Chacra ${ }^{1}$, entre los años 2013 y 2017. La investigación siguió específicamente un conflicto por relocalizaciones que se desarrolló en dicho período, concretamente durante los años 2014 y 2015, y que se originó con motivo de una obra de infraestructura hidráulica llevada adelante por el Ministerio de Infraestructura. Seguir este conflicto desde un enfoque etnográfico (Peirano, 2004) implicó la realización de entrevistas abiertas, charlas informales, recopilación y análisis de publicaciones en redes e informes por parte de los actores involucrados en el conflicto, y fundamentalmente de observaciones participantes en asambleas en el barrio, reuniones con funcionarios, "mesas chicas" con los actores que llevarían adelante la demanda al Estado, recorridos por la ciudad cuando se evaluaban destinos posibles para la relocalización.

De este trabajo de campo se recuperarán en este artículo aspectos generales del barrio y del devenir del conflicto como material para pensar las modalidades de intervención del Estado provincial allí. El objetivo, como sostuve, es analizar el rol que asumió el Estado —en este caso, el Estado provincial a través de sus representantes en el Ministerio de Infraestructura- en la gestión de la obra pública y la relocalización ${ }^{2}$. El artículo buscará mostrar cómo el conflicto que se desató en el barrio se asentó sobre una doble incertidumbre: una incertidumbre coyuntural vinculada con las modalidades de intervención del Estado en torno a la obra y una incertidumbre estructural vinculada con las condiciones de vida de
1. Los nombres propios han sido modificados para preservar el anonimato.

2. Se utilizará en este artículo la categoría de "Estado" con fines prácticos para hacer referencia a la intervención de un conjunto de actores institucionales específicos que actúan en representación de organismos estatales, en este caso provinciales, pero entendiendo que no se trata de un todo homogéneo. El Estado como categoría plural, fragmentaria y no unívoca ha sido trabajada en BALERDI (2020). 
los habitantes de La Chacra. En paralelo, se buscará reflexionar sobre el rol de este tipo de políticas al habilitar demandas populares en torno al derecho a la tierra y la vivienda, a la vez que al contribuir a modelos desiguales de ciudad.

\section{Relocalización, conflicto e incertidumbre}

El barrio La Chacra, un pequeño asentamiento emplazado sobre los márgenes de un arroyo que cruza la periferia de la ciudad de La Plata, fue el escenario de un conflicto motivado por el desarrollo de una obra de infraestructura hidráulica a partir del año 2014. El 2 de abril de 2013 tuvo lugar una trágica inundación en La Plata que se cobró la vida de decenas de personas y afectó a miles de viviendas en la ciudad y sus alrededores. Si bien la causa inmediata de la inundación fue la abundancia y celeridad de las precipitaciones que cayeron durante ese día, las interpretaciones posteriores del evento la atribuyeron a la ausencia de obras hidráulicas adecuadas y preventivas que permitieran el escurrimiento de los arroyos.

El arroyo El Gato, sobre cuyos márgenes se ubica el barrio La Chacra, fue uno de los más desbordados de la zona, y se convirtió entonces en el foco principal de un ambicioso plan de infraestructura hidráulica implementado a partir de 2014 por el Ministerio de Infraestructura de la provincia de Buenos Aires, diseñado con el objetivo de evitar futuras inundaciones. La obra, que preveía el ensanchamiento y canalización del arroyo, implicaría como consecuencia la necesidad de liberar sus márgenes. Para ello el plan diseñado por el ministerio contaba con la realización de viviendas en otro predio de la ciudad, a las que serían relocalizadas las familias cuyas casas debían ser removidas para el avance de la obra.

El conflicto se inició en La Chacra en un clima de incertidumbre generado por la ausencia de información oficial respecto de la futura e inminente relocalización. En este marco, se fue tramando una red híbrida (Melé, 2016) que no existía previamente en el barrio, y que fue enlazando a distintos actores - habitantes del barrio, pero también extensionistas universitarios, militantes de una organización territorial, integrantes de un colectivo de abogados-, que se involucraron en un reclamo ante el Ministerio de Infraestructura.

La Chacra está conformado por migrantes chaqueños de origen qom y migrantes paraguayos que se han ido estableciendo de manera informal desde principios de los años 2000. 
En términos generales, la gran mayoría de los habitantes del barrio comparte trayectorias atravesadas por procesos migratorios, el abandono temprano de la educación formal, el ingreso temprano al mercado laboral y el pasaje intermitente por distintos trabajos informales, fundamentalmente en la construcción, el servicio doméstico, así como también el cartoneo, la venta de ropa usada en ferias, el corte de césped y otras “changas”. El barrio presenta dificultades extendidas vinculadas con la precariedad de las viviendas, la falta de servicios públicos, como electricidad y agua potable, la recolección regular de residuos y de sistemas cloacales. A pesar de esto, en los últimos años las familias fueron recibiendo nuevas fuentes de ingreso (centralmente la Asignación Universal por Hijo y los ingresos otorgados a través de las cooperativas de empleo, como el "Argentina Trabaja” y "Ellas Hacen”), que mejoraron relativamente su situación. Esto, sumado a la circulación por el barrio de nuevos recursos materiales otorgados por distintas áreas del Estado y distribuidas por organizaciones territoriales, condujo a cambiar notablemente en poco tiempo su morfología: las casillas de chapa y madera que habían levantado las familias al llegar fueron dejando paso a viviendas más amplias y de material.

Este fue el escenario del conflicto que se desplegó en torno a un proyecto de relocalización, y cuyo análisis permitirá dar cuenta de algunas de las características que asumió la intervención del Estado provincial en la producción del espacio urbano segregado en la ciudad de La Plata en este contexto. A mediados de 2014, el Ministerio de Infraestructura dio curso a la obra hidráulica que sería llevada adelante por la Dirección provincial de Saneamiento y Obras Hidráulicas, que era parte de la Subsecretaría de Obras Públicas del ministerio. La obra tenía el objetivo principal de mejorar la capacidad de escurrimiento de uno de los arroyos que se había visto más desbordado durante la inundación del año anterior. Con este fin, se preveía su ensanchamiento y canalización a lo largo de unos 13 kilómetros. El plan de obra preveía también la relocalización de cientos de viviendas asentadas en los márgenes del arroyo que “obstaculizaban” de momento su ensanchamiento. Esto estaría a cargo del Instituto de la Vivienda, el cual formaba parte del ministerio. El proyecto de relocalización previsto suponía la construcción de más de 400 viviendas, financiadas en su mayoría por el Plan Federal de Urbanización de Villas y Asentamientos Precarios ${ }^{3}$, en un único predio para trasladar a diversas familias de todos los barrios que se asentaban a lo largo del arroyo.

De todo esto, sin embargo, los habitantes de La Chacra no tenían información. Como comprenderían luego, las distintas áreas del ministerio articuladas en esta gran obra
3. El Plan Federal de Urbanización de Villas y Asentamientos Precarios, establecido en 2005, era gestionado por la Dirección de Políticas Habitacionales de la Subsecretaría de Desarrollo Urbano y Vivienda, organismo dependiente de la Secretaría de Obras Públicas del Ministerio Nacional de Planificación Federal, Inversión Pública y Servicios. A través de este programa, el Estado Nacional, en coordinación con los organismos provinciales de Vivienda, financiaba la construcción y el mejoramiento de viviendas y de obras de infraestructura para el mejoramiento del hábitat urbano. Ver BETTATIS (2009). 
irían construyendo "el dato" respecto de qué viviendas relocalizar "sobre la marcha", como reconoció uno de los funcionarios, a medida que la canalización y ensanchamiento del arroyo avanzaba. En este marco, cuando las primeras máquinas excavadoras comenzaron a trabajar en el arroyo, ya a pocos metros del barrio, y ningún funcionario se había acercado aún a informar a los vecinos sobre cuántas y cuáles serían las familias que se iban a relocalizar o cuál sería el destino y las condiciones de la relocalización, un clima de temor e incertidumbre se instaló en el barrio. El conflicto se asentó así sobre una incertidumbre coyuntural vinculada con la modalidad específica de intervención del Estado en torno a la obra y a la relocalización: primordialmente inconsulta y sin la participación de los habitantes en su diseño o implementación.

\subsection{Incertidumbre coyuntural}

La incertidumbre marcó los primeros tiempos del conflicto, cuando las incertezas sobre la relocalización y la falta de información precisa se agravaban por la presencia de las máquinas excavadoras en el arroyo, que trabajaban ya a unas pocas cuadras del asentamiento. Las noticias sobre una inminente relocalización circulaban por entonces solo a través de rumores y datos parciales en conversaciones cotidianas. No se sabía si sería todo el barrio el que debería trasladarse o solo algunas familias, cuál sería el destino de los relocalizados, las condiciones de la relocalización, ni los plazos. En este clima de incertidumbre, la relocalización aparecía como amenaza.

"Si no me ubicas a dónde irme con mi familia, no me puedo ir a la calle. A mí no me dieron ninguna solución", sostenía preocupado Roberto en el marco de una de las primeras asambleas que se organizaron entre los vecinos del barrio para compartir los pocos datos que circulaban sobre la relocalización por entonces (registro de campo, noviembre de 2014). La posibilidad de que sus viviendas tuvieran que ser removidas bajo cualquier circunstancia y sin ninguna alternativa aparente a cambio generaba temor entre los habitantes de La Chacra.

Nosotros estábamos asustados - recuerda Carmen, una de las vecinas del barrio-, porque se decía que iban a llegar las máquinas, las topadoras, iban a empezar a tirar casas.

Se decía que en toda la tierra que estaba al lado del arroyo supuestamente se sabía que no había que hacer casas -agregaba Gabriela, su cuñada- porque le correspondía al Estado... que por eso no nos habían avisado nada, que por eso se mandaban las máquinas y iban a venir a romper casas, todo (entrevista con Carmen y Gabriela, diciembre de 2015). 
La falta de participación de los beneficiarios de las políticas habitacionales en el diseño e implementación de estas no es algo novedoso (Eguía ET AL., 2018), e incluso se identifica como una de las continuidades de las modalidades de intervención del Estado en materia habitacional en relación con las décadas anteriores (CRAvino, 2017).

Aquella era la segunda asamblea que se realizaba en el barrio entre los vecinos con motivo de la relocalización. Por entonces circulaban rumores de que algunos habían recibido la visita de funcionarios del Instituto de la Vivienda, instándolos a que aceptaran una propuesta, aún incierta, de traslado. Gabriel, uno de los jóvenes de la calle 141, tomó la palabra visiblemente enojado. Contó que en el mes de diciembre había ido "gente del ministerio" a informarles a él y a tres personas más también presentes en la asamblea (Matías, Carlos y Juliana) y a los habitantes de otras dos viviendas (en total seis casas) que iban a tener que mudarse. Matías confirmó las palabras de Gabriel. Ambos se mostraban molestos, y contaron que les habían ofrecido trasladarse "a una casilla en Romero o a un terreno en barrio Aeropuerto", pero que a ellos ninguna de estas opciones les gustaba. Sumaron, para completar el relato, que sospechaban incluso de la veracidad de estas alternativas, ya que los funcionarios no les dieron "ninguna garantía". "Nos mienten”, sostuvo Gabriel indignado. "Nos dijeron que nos iban a llamar a una reunión el 15 de enero, y seguimos esperando". "Ya estamos en febrero, y no vinieron más", agregó Matías confirmando la acusación de Gabriel. Jimena se sumó al relato de Gabriel y Matías y dijo haber manifestado a los funcionarios no querer dejar su casa, y que a cambio recibió la amenaza de "te vamos a pasar con la topadora por arriba si no te movés” (registro de campo de asamblea, febrero de 2015).

En este marco, las primeras acciones de una red de actores que comenzó a tramarse en el barrio en este clima de incertidumbre se orientaron a reclamar a los funcionarios por información oficial y precisa respecto de las condiciones de la relocalización. Principalmente, miembros de un proyecto de extensión universitaria, militantes de una organización social que desarrollaban un trabajo territorial en La Chacra y abogados de un colectivo de acción jurídica local, alertados por la preocupación de los habitantes, comenzaron a articularse con el fin de solicitar a los funcionarios del ministerio que brindaran información sobre la relocalización. Así, se fueron estableciendo los primeros diálogos con los funcionarios y se fueron conociendo algunos primeros datos sobre la relocalización. Estos mostrarían prontamente las consecuencias negativas de esta modalidad inconsulta de intervención. Por un lado, el número de familias para relocalizar por cada uno de los barrios asentados 
sobre los márgenes del arroyo sería establecido en función de lo que el área de Hidráulica del Ministerio definiera, siguiendo los requerimientos técnicos del ensanchamiento y canalización. En principio, como muestra el registro de campo anterior, estaban señaladas solo unas seis viviendas para el caso de La Chacra. Esto hizo surgir la preocupación entre los vecinos sobre el resquebrajamiento de los lazos familiares y vecinales que supondría para el barrio la relocalización de solo algunas pocas de las viviendas. “¿Cómo hago para ir yo allá estando sola — preguntaba Jimena preocupada— siendo que acá está mi mamá, están mis parientes, están todos? ¿Qué hago yo sola allá en el medio de la nada?” (registro de campo de asamblea, marzo de 2015).

Por otro lado, la relocalización fue propuesta inicialmente a un destino que los propios habitantes rechazaron. El proyecto de relocalización previsto en el plan de obra del Ministerio suponía, como sostuve, la construcción de más de 400 viviendas en un único predio para trasladar a todas las familias que debieran ser relocalizadas de los márgenes del arroyo. Este predio estaba localizado en un barrio periférico conocido como El Mercadito. Las casas que el ministerio construía allí iban siendo otorgadas a grupos reducidos de familias provenientes de distintos barrios. El gran complejo habitacional iba convirtiéndose así en un bricolaje de habitantes con distintas trayectorias, inserciones, redes, que eran desprendidos de sus entramados y vínculos locales y reinsertados aleatoriamente en otros.

Durante el conflicto en La Chacra y el proceso de negociaciones con los funcionarios del ministerio para determinar las condiciones de la relocalización, circulaban sin cesar en el barrio rumores y anécdotas sobre situaciones de violencia y discriminación entre los residentes ya establecidos en El Mercadito y los nuevos que iban llegando a medida que las relocalizaciones se producían. Los temores, especialmente de los habitantes paraguayos, ante amenazas de expulsión de las nuevas viviendas justificadas por sentimientos de xenofobia y racismo por parte de los argentinos ya establecidos condujeron a que los habitantes del barrio rechazaran de plano este lugar como destino de su relocalización.

Mi primo — relataba Jimena durante el conflicto— se estaba por mudar al Mercadito [aceptando la oferta de los funcionarios], y después fue a ver las casas nuevas y lo sacaron cagando. Él fue un día, me acuerdo, con Matías, el otro chico de allá que también se tenía que mudar. Fueron y no los dejaron entrar al barrio: "No, porque ustedes son paraguayos [les dijeron], porque ustedes no van a entrar acá, y si llegan a venir los vamos a cagar a tiros” [...] Yo acá [en La Chacra] 
tengo a mi prima, o sea, somos todos parientes, yo salgo y hablo con este, con este, con este. Ponele, yo tengo una urgencia o cualquier cosa, yo puedo dejar a mi hija con mi mamá. Vos acá a la madrugada dormís tranquila, no te pasa nada, allá en el Mercadito andá a saber qué puede pasar... porque a nosotros mucho no nos quieren porque somos paraguayos (entrevista con Jimena, septiembre de 2015).

Esta particular modalidad de intervención del Estado en la producción del espacio urbano, configurando un bricolaje territorial sin atender a desarraigos y convivencias forzadas, contribuye al "crecimiento de las desigualdades dentro del mismo territorio" (PréVôt SchAPIRA, 2001, p. 48). La segregación residencial se reactualiza así bajo una nueva forma que ya no se circunscribe únicamente al modelo de centro/periferia como espacios homogéneos. Como sostiene Prévôt SchapIRA para el caso de Buenos Aires:

hoy en día, la espacialización de la pobreza ya no debe pensarse solamente en términos de enclave, sino más bien en términos de gradación, como un fenómeno que alcanza a una amplia parte del territorio y que acentúa las fronteras entre los diferentes barrios, incluso entre las manzanas, yendo así en contra de la representación clásica de la pobreza, en una ciudad donde las villas miseria habían sido y continúan siendo para muchos gestores de políticas sociales el modo de designación del problema (2001, p. 48).

Finalmente, la posibilidad de negociar otros destinos potenciales para la relocalización de los vecinos de La Chacra se debió, en gran parte, al peso que fue ganando la red de actores del reclamo como interlocutora válida ante los funcionarios del ministerio. Estos nuevos destinos, sin embargo, tenían ciertas limitaciones. Las relocalizaciones debían llevarse a cabo en tierras fiscales, ya que - según explicaban los funcionarios- los elevados precios de la tierra de mercado hacían imposible al Estado provincial adquirir los lotes necesarios. Ahora bien, dada la escasez en materia de tierra fiscal disponible, las opciones posibles de destino propuestas por los funcionarios fueron pocas, en zonas periféricas, estigmatizadas, catalogadas de "inseguras" por los propios habitantes de La Chacra, quienes se negaban a ser relocalizados allí. Este rechazo se vio reforzado, además, porque estos destinos propuestos se ubicaban también en la periferia platense, pero más alejados del centro que La Chacra, lo que implicaba para los vecinos un desarraigo no solo de las tramas familiares que los contenían, sino también de los espacios y circuitos por los que transitaban cotidianamente. Cravino (2012) sostiene que para muchos de los habitantes populares que se mudaron de barrio en el marco de planes habitacionales del Programa Federal de Construcción 
de Viviendas implementado a partir del 2004 esto implicó la "posesión de un capital locacional devaluado" (p. 117). Estos nuevos barrios fueron construidos en la periferia de la ciudad, "en los vacíos que rodeaban el espacio urbanizado" (p. 113), lo que implicó para los vecinos mudados mayores dificultades que antes en el acceso al transporte público y también a las escuelas y centros de salud de la zona, que no habían sido preparados para recibir a esta nueva cantidad de personas.

\subsection{Incertidumbre estructural}

La relocalización implicaba el otorgamiento de viviendas en propiedad legal a sus nuevos habitantes, a través de los recursos del Plan Federal de Urbanización de Villas y Asentamientos. Esto representaba un elemento de gran interés para los vecinos de La Chacra, que vivían en condiciones de irregularidad en la tenencia de sus tierras y viviendas, al margen de un arroyo contaminado e inundable. No obstante, la relocalización no cumplía con sus necesidades, en la medida en que, si bien representaba la oportunidad de obtener la titularidad de una vivienda, contribuía asimismo a reforzar su segregación residencial al proponer la edificación en otro barrio desfavorecido y estigmatizado de la periferia platense. Como sostiene SEGURA (2014), los programas habitacionales que se implementaron en Argentina luego de 2003 han tenido un impacto en la segregación residencial

en la medida en que habitualmente se limitan a la construcción de viviendas en la periferia metropolitana, donde hay suelo disponible y barato, carente de infraestructura, lejos de los servicios y que insumen a sus pobladores gran cantidad de tiempo, de dinero y de energía en los desplazamientos. Sin minimizar lo que significa acceder a una vivienda, no podemos perder de vista el rol de estas políticas estatales paliativas en la profundización de las dinámicas de segregación y fragmentación del espacio urbano que [...] a mediano plazo podrían tener un rol clave en la reproducción de la desigualdad urbana en lo que respecta al aislamiento social, la desconexión del mercado de trabajo formal, el acceso a educación y los estigmas sociales (SEGURA, 2014, p. 22).

Esto se debe en gran parte a que las posibilidades de gestión del territorio por parte del Estado a través de estas políticas se han visto enormemente condicionadas por la persistencia de las lógicas del mercado inmobiliario en la regulación del espacio. Así, como sostienen Di Virgilio y Rodríguez (2018, p. 194), al priorizarse en la mayoría de los casos la producción empresarial de obra nueva, "las localizaciones son periféricas y se encuentran poco integradas a la trama urbana”. 
En los primeros meses del conflicto, antes de que se iniciaran las negociaciones con los funcionarios, las preocupaciones de los habitantes de La Chacra estaban asociadas a posibles desalojos. Ante el clima de incertidumbre ocasionado por la desinformación y la inconsulta, la imagen de las amenazantes "topadoras" que arrasaban las viviendas a su paso - que reflejaban los relatos de Gabriela y Carmen anteriormente citados- no era infundada. "Nuestra mayor preocupación —-sostenía una de las abogadas que formaba parte de la red de actores del reclamo- es que mientras transcurren las negociaciones para definir un posible destino de relocalización, el ministerio sigue interviniendo en el territorio con aprietes". "La gente - advertía - se ve en la necesidad de tomar decisiones apuradas para que no le pasen con la topadora por encima" (registro de reunión con funcionarios, abril de 2015).

[La funcionaria del Instituto] viene todos los días y te dice "vos no tenés derecho, vos estás en una tierra que es del Estado, vos te tenés que ir". Yo tengo una casa de material que me costó mucho construir, pero ella me dice que no vale nada porque está sobre una tierra que es del Estado, me dice que tendría que haberla hecho en otro terreno... yo si tuviera plata me hubiera comprado un terreno, pero no tengo (Jimena, registro de campo de asamblea, abril de 2015).

El temor siempre presente de que esto suceda estaba vinculado con las condiciones de hábitat de las familias, que se habían ido asentando en el barrio y no poseían la titularidad de esas tierras. Esto configuraba para los vecinos no solo un particular modo de habitar el barrio, sino también un vínculo específico con el Estado.

Los orígenes de La Chacra, en torno al año 2000, no se remontan —como sí sucede en muchos otros barrios populares de la ciudad - a una toma colectiva y organizada de la tierra. El barrio presenta la particularidad de haberse ido conformando paulatinamente a partir de la llegada, por un lado, de familias provenientes del Chaco que comenzaron a asentarse en el terreno a partir de redes y lazos de parentesco y, por otro, de familias provenientes de Paraguay que no tenían originalmente en su mayoría vínculos parentales con sus vecinos y fueron llegando al barrio mediante el alquiler o la compra de las viviendas a habitantes anteriores. Desde entonces, y en gran medida a través de recursos distribuidos en el barrio por distintas áreas del Estado provincial y nacional (materiales de construcción, principalmente), a partir de mediados de la década de 2000, y la llegada continua de nuevos habitantes provenientes del Chaco y Paraguay, el barrio se fue conformando y creciendo ininterrumpidamente. 
4. Carolina Maidana (2009) sostiene que el proceso de industrialización y ampliación de la frontera agrícola posterior al fin de la Segunda Guerra Mundial implicó nuevos desafíos para la población qom del Chaco que dieron lugar, siguiendo el concepto propuesto por

LiLIANA TAMAGNo (2001),

a múltiples "respuestas/ resistencias", entre las cuales una importante fue la migración. Las migraciones indígenas son, en este sentido, "un fenómeno

recurrente y constante [...] históricamente relacionado con la expansión colonialy, por lo tanto, inescindible de los violentos y traumáticos procesos de destierro y expropiación a los que se vieron y aún se ven sometidos los pueblos indígenas" (MAIDANA, 2009, p. 46).
El vínculo de los habitantes de La Chacra con el Estado en torno al hábitat se fue configurando tanto a partir de los recursos materiales obtenidos para la mejora de sus viviendas en los últimos años como en virtud de las dificultades —de más largo alcance- sufridas en el acceso a la propiedad de la tierra, lo que muchas veces los ha enfrentado al temor de su erradicación. Ahora, si bien La Chacra nunca ha sido desalojado, muchos de sus habitantes cargan con experiencias previas o conocen relatos ajenos de desalojos forzosos a manos de las fuerzas policiales. A esto se suma, para los vecinos qom del barrio, la historia (cercana) de las expulsiones de comunidades indígenas en la provincia de Chaco ${ }^{4}$. La experiencia de los habitantes de La Chacra con el Estado está tramada entonces por una compleja acumulación de sentidos y experiencias heterogéneas que son propias, como sostienen Cecilia Ferraudi Curto y Pablo Semán (2016, p. 150), del proceso histórico que conforma las “camadas geológicas" de lo popular en Argentina: "desde el largo plazo de las pérdidas y la decadencia hasta el tiempo relativamente breve de las mejoras moderadas".

Así, la incertidumbre coyuntural asociada al modo particular en que circuló la información sobre la obra y sus posibles consecuencias para el barrio se articuló también con una incertidumbre estructural derivada de las particulares condiciones de vida de los vecinos: la irregularidad en la tenencia de los terrenos o las viviendas en los que habitan, sumada a la precariedad en las condiciones materiales y de infraestructura del barrio y su cercanía a la cuenca de un arroyo contaminado e inundable los pone frente a una constante incerteza sobre la continuidad y características de su lugar de residencia, y hace del desalojo forzoso tanto como de la obtención de una vivienda por parte del Estado dos opciones igualmente posibles.

\section{El Estado habilitante del reclamo}

Con el correr de los meses, y a partir de que el reclamo fue ganando mayor envergadura, nuevos funcionarios del ministerio asumieron el rol de interlocutores con la red: representantes de un área de la Subsecretaría de Tierras que solía ocuparse de este tipo de conflictos. Esto fue habilitando nuevas condiciones para la relocalización.

En una de las primeras asambleas mantenidas con los funcionarios de Tierras, uno de ellos, Emanuel, reconoció que el ministerio estaba “urgido" porque la obra avanzara, pero 
sostuvo que como representantes de la subsecretaría, con las "competencias necesarias para generar suelo urbano" estaban dispuestos a "no descartar ninguna alternativa que se proponga como solución” (registro de campo, junio de 2015).

En la medida en que los funcionarios se mostraron dispuestos a aceptar un nuevo destino para la relocalización que los actores de la red propusieran, aquella dejó de ser percibida como una amenaza y se transformó para los propios vecinos en una oportunidad: la ocasión de dejar de vivir al lado de un arroyo contaminado e inundable, de obtener una vivienda más amplia y mejor que la que poseían y, claro, de contar con su titularidad. Como explicó el referente de la organización territorial ante este nuevo escenario: "en la asamblea con los vecinos se charló sobre la posibilidad de aprovechar la coyuntura para dejar de vivir al margen del arroyo y pelear por algo mejor" (registro de campo, junio de 2015).

Entonces, el reclamo que se había iniciado como una demanda por información se convirtió en una petición para ampliar la noción de afectación: si se lograba que se tuviera en cuenta como "afectados" por la obra a un número mayor de vecinos que los que inicialmente los funcionarios consideraban (porque sus viviendas se hallaban igualmente ubicadas sobre el margen del arroyo que aquellas seis casas identificadas en un principio), se conseguiría negociar un mayor número de personas para relocalizar. "Las familias están dispuestas a moverse en bloque", sostuvo el referente de la organización en una de las reuniones mantenidas con los funcionarios de Tierras. "En este marco, y habiendo tierras disponibles, lo que hay que hacer es charlar números. Dadas todas estas condiciones, la solución depende de una decisión política” (registro de campo, junio de 2015). Ser "afectado" ya no implicará solo el perjuicio de vivir en un barrio periférico, al margen de un arroyo contaminado, ante la perentoria necesidad de la relocalización para el avance de una obra que promete beneficios para la ciudad formal, sino que se transformará en una categoría de reconocimiento: de aquellos que merecían ser incluidos en una relocalización que les garantizara el derecho a la tierra y una vivienda digna.

En los procesos de desalojo y relocalización de las villas asentadas en la cuenca Matanza-Riachuelo en Buenos Aires, CARMan (2015) afirma que ser "afectado" describe tres dimensiones relacionadas del padecimiento que el propio hábitat y el proyecto de relocalización imponen a los habitantes: son afectados por la imposición de tener que ser 
prontamente relocalizados, pero también por vivir próximos a una cuenca contaminada y por padecer las consecuencias físicas de esa contaminación. Si bien las condiciones del hábitat y la situación particular en relación con la relocalización de los vecinos de La Chacra son similares a las que estudia CARMAn, el sentido etnográfico que adquiere la categoría de “afectación” en este caso se reveló diferente. A partir de la acción de la red de actores del reclamo, una categoría que en principio solo tendría connotaciones negativas ("afectados" referiría a un colectivo del que nadie quisiera ser parte) es resignificada: ser afectado se convierte en una categoría de reconocimiento que la red de actores demanda al Estado para aquellos a quienes se espera poder incluir en la relocalización.

Finalmente, los nuevos interlocutores de la Subsecretaría de Tierras se presentaron dispuestos a aceptar el criterio de afectación propuesto por la red de actores del reclamo y a negociar las condiciones de una relocalización ampliada. Y en la medida en que no se demandó una vivienda en cualquier sitio, sino que el reclamo se fue tramando a partir de los propios criterios de los habitantes sobre qué es un buen barrio, qué condiciones debe cumplir, qué aspectos espaciales pero también sociales deben priorizarse (seguridad, acceso a servicios, comunicación con el centro, pero también promesas de buen recibimiento por parte de los residentes ya establecidos de dichos barrios, entre otras cosas), esta se constituyó como una demanda por el derecho a la ciudad que la política implementada habilitó.

\subsection{Un nuevo ciclo político y el final de la relocalización colectiva}

El proceso analizado se desarrolló en un momento de quiebre del ciclo político iniciado en el año 2003. Este contexto y la modalidad con que se había desarrollado la intervención provincial en el caso condujeron a que - a pesar de que con los nuevos interlocutores de la Subsecretaría de Tierras la resolución colectiva al conflicto parecía haberse encaminado- la relocalización colectiva de los habitantes de La Chacra igualmente no se produjera. Por un lado, como sostuve, el alto precio de las tierras en el mercado supuso que los destinos posibles para llevar a cabo la relocalización se limitaran a tierras fiscales, en zonas desfavorecidas, alejadas del centro y de los canales de circulación cotidianos de los habitantes. Por otro lado, el hecho de que los habitantes no hubiesen sido participados desde un comienzo contribuyó a demorar el proceso, dado que los funcionarios se encontraron con la negativa de aquellos a ser relocalizados a los destinos que estos proponían inicialmente. En consecuencia, las negociaciones para definir las nuevas condiciones de la relocalización ocuparon varios meses. 
La obra hidráulica que estaba llevando adelante el Ministerio de Infraestructura de la provincia nada menos que en la ciudad capital era uno de los pilares de la campaña del gobernador Daniel Scioli, quien sería el candidato por el oficialismo a la presidencia en las elecciones generales de 2015. Para los funcionarios, la obra debía avanzar y concluirse antes de los comicios electorales. Sin embargo, las dificultades mencionadas por encontrar un terreno apto para llevar a cabo la relocalización colectiva condujeron a que esta finalmente no pudiera concretarse. Los comicios resultaron en la derrota del oficialismo a tres escalas: nacional, provincial y municipal. El recambio de los funcionarios en el área de Infraestructura supuso la pérdida de los canales de interlocución construidos hasta entonces en torno al conflicto. El nuevo gobierno provincial desarticuló la política de vivienda trasladando la Subsecretaría de Tierras al Ministerio de Desarrollo Social. A nivel nacional, una tendencia hacia la cada vez mayor participación del sector privado contribuyó a partir de 2015 a la "mercantilización de la vivienda social sobre la concepción de derecho social que primaba anteriormente” (BARRETO, 2018, p. 430).

\section{Consideraciones finales}

Este artículo buscó reflexionar sobre el rol de las políticas habitacionales desplegadas hasta el año 2015, a partir de un caso concreto en la ciudad de La Plata: un conflicto por relocalizaciones en un barrio popular de la periferia. Si bien el proyecto de relocalización de algunas de las viviendas de este barrio estuvo motivado por el desarrollo de una obra hidráulica para la prevención de inundaciones, este proyecto echó mano de una de las principales políticas habitacionales que venía desarrollando el gobierno nacional desde el año 2005, el Plan Federal de Urbanización de Villas y Asentamientos, implementado y gestionado en este caso por el gobierno provincial a través del Ministerio de Infraestructura.

Se buscó mostrar que las modalidades particulares que asumió la gestión de esta política habitacional tuvieron algunas consecuencias ambivalentes para los actores implicados. La relocalización comenzó a desarrollarse de modo inconsulto y sin la participación de los propios destinatarios en su diseño o implementación, intervención caracterizada por lo que llamé una incertidumbre coyuntural. Esta se articuló con y tendió a reforzar una incertidumbre estructural vinculada con las condiciones habitacionales de los vecinos de La Chacra de más largo alcance: vivir al borde de un arroyo contaminado e inundable, en muchos casos sin contar con la titularidad de las viviendas que habitan, con el temor siempre presente al desalojo. 
Esta modalidad de intervención proyectaba la relocalización de las familias a un barrio al que estas no deseaban ir - también en la periferia platense, alejado de sus tramas de circulación cotidiana, estigmatizado como barrio peligroso e inseguro-contribuyendo a reforzar una modalidad de segregación residencial que ya no diferencia -como espacios homogéneos- a la periferia pobre del centro rico, sino que establece desigualdades en el interior de esta, por ejemplo, entre residentes establecidos y nuevos o nativos y migrantes.

Como consecuencia, esto supuso el rechazo inicial por parte de los habitantes de La Chacra del destino de la relocalización propuesto por los funcionarios, lo que a su vez condujo a que se dilataran los tiempos proyectados para la relocalización. Al mismo tiempo, esto habilitó un conflicto y las negociaciones para una solución colectiva, lo que permitió que la relocalización, percibida inicialmente como una amenaza se transformara en una oportunidad. Así, el Estado funcionó como habilitante de un reclamo (cosa que cambiaría a partir de 2015), y los habitantes lo aprovecharon: articulados en una red junto a otros actores, desplegaron estrategias de acción ante la incertidumbre en que esa modalidad de intervención los sumía. Se movilizaron en y por esa incertidumbre coyuntural, para reclamar por información oficial y precisa, y luego para cuestionar y modificar las condiciones de relocalización que los funcionarios proponían, buscando transformar de ese modo la incertidumbre estructural que sus condiciones de hábitat les imponían.

Finalmente, los tiempos marcaron el desenlace del conflicto: las dificultades para acordar un destino para la relocalización, que cumpliera con los criterios de los habitantes pero también con las limitaciones del Estado provincial en cuanto a la disponibilidad de tierras fiscales, demoraron la resolución. El quiebre del ciclo político y la pérdida de los interlocutores de un Estado que habilitaba el reclamo condujeron al fin de la relocalización como oportunidad para los habitantes de La Chacra. La obra hidráulica siguió su paso, y las viviendas continuaron localizadas allí, ahora aún más al borde de un peligroso canal de cemento de unos tres metros de profundidad.

El análisis de este caso nos permite sostener una vez más la necesidad de involucrar activamente a los beneficiarios en el diseño e implementación de las políticas habitacionales, y a la vez de que la producción pública del hábitat encuentre otras lógicas que escapen a los condicionamientos del mercado inmobiliario del suelo. 


\section{Referencias}

BALERDI, S. (2020). Las redes del hábitat. Demandas colectivas y conflictos urbanos. EDULP.

BARRETO, M. Á. (2012). Cambios y continuidades en la política de vivienda argentina (2003-2007). Cuadernos de vivienda y urbanismo, 5(9), 12-30.

BARRETO, M. Á. (2018). La política habitacional de Cambiemos: el retorno de la mercantilización de la vivienda social en Argentina. Estudios Demográficos y Urbanos, 33(2), 401-436.

BETTATIS, C. (2009). Urbanización de asentamientos informales en la provincia de Buenos Aires. Bitácora, 15(2), 89-108.

CARMAN, M. (2015). Una mirada sobre cuerpos sufrientes: Las relocalizaciones de villas ribereñas en Buenos Aires. Anuario de Antropología Social y Cultural en Uruguay, 13, 65-74.

CRAVINO, M. C. (2012). Construyendo barrios. Transformaciones socioterritoriales a partir de los Programas Federales de Vivienda en el Área Metropolitana de Buenos Aires (2004-2009). CICCUS / UNGS.

CRAVINO, M. C. (2017). La cuestión de la vivienda en el Área Metropolitana de Buenos Aires (2003-2008). Ciudadanías. Revista de Políticas Sociales Urbanas, 1, 35-47.

DI CROCE GARAY, A. \& ALESSIO, A. (2018). Tomas de tierras en La Plata. Avances de un Registro de Tomas de Tierras para el período 2000-2015. Crítica y Resistencias. Revista de conflictos sociales latinoamericanos, 6, 18- 46.

DI VIRGILIO, M. M. \& RODRÍGUEZ, M. C. (2018). Hábitat, vivienda y marginalidad residencial. En Piovani, J. I. y Salvia, A. (Coord.), La Argentina en el siglo XXI. Cómo somos, vivimos y convivimos en una sociedad desigual. Siglo XXI.

DUHAU, E. (2013). La división social del espacio metropolitano. Una propuesta de análisis. Revista Nueva Sociedad, 243, 79-91.

EGUÍA, A., ORTALE, S. \& RUASKY, M. E. (2018). El problema del acceso a la vivienda en sectores pobres: un estudio sobre la implementación del Programa Federal de Viviendas en la periferia de la ciudad de La Plata. En Ortale, S. y Rausky, M. E. (Coords.). Políticas sociales, desigualdades y vulnerabilidades: Estudios de caso en el Gran La Plata (pp. 217- 242). La Plata: Universidad Nacional de La Plata. Facultad de Humanidades y Ciencias de la Educación. Recuperado de: https://ibros.fahce.unlp.edu.ar/index.php/libros/ catalog/book/114 
FERRAUDI CURTO, M. C. (2014). Ni punteros ni piqueteros: Urbanización y política en una villa del conurbano. Gorla.

FERRAUDI CURTO, M. C. \& SEMÁN, P. (2016). Los sectores populares. En G. Kessler (Comp.), La sociedad argentina hoy: Radiografía de una nueva estructura. Siglo XXI.

GONZÁLEZ, P. (2014). La urbanización informal en el Gran La Plata. Un análisis de sus rasgos estructurales en el contexto posneoliberal (2003- 2011). En Badenes, G. y Marín, M. A. (Comps.), X Bienal del Coloquio de Transformaciones Territoriales. Desequilibrios regionales y políticas públicas: una agenda pendiente (pp. 1244-1257). Editorial de la UNC.

KESSLER, G. (2014). Controversias sobre la desigualdad. Argentina, 2003-2013. Fondo de Cultura Económica.

MAIDANA, C. (2009). Volver a la tierra: Parentesco, redimensionalización territorial y reconstrucción identitaria. En: L. Tamagno (Coord.), Pueblos indígenas: Interculturalidad, colonialidad y política. Biblos.

MELÉ, P. (2016). ¿Qué producen los conflictos urbanos? En F. Carrión \& J. Erazo (Coord.), El derecho a la ciudad en América Latina: Visiones desde la política. (pp. 127-157). UNAM.

PEIRANO, M. (2004). A favor de la etnografía. En: A. Grimson; G. Lins Ribeiro \& P. Semán (Coord.), La antropología brasileña contemporánea: Contribuciones para un diálogo latinoamericano. Prometeo.

PRÉVÔT SCHAPIRA, M. F. (2001). Fragmentación espacial y social: conceptos y realidades. Perfiles latinoamericanos, 19, 33-56.

SEGURA, R. (2014). El espacio urbano y la (re)producción de desigualdades sociales. Desacoples entre distribución del ingreso y patrones de urbanización en ciudades latinoamericanas. Working Paper Series No. 65, desiguALdades. net. Research Network on Interdependent Inequalities in Latin America, Berlin.

TAMAGNO, L. (2001). Nam Qom Huetáa Na dockshi Lma'. Los tobas en la casa del hombre blanco. Identidad, memoria y utopía. Ediciones Al Margen. 